\title{
Contribution of Imaging to Cancer Care Costs
}

\author{
Yang Yang and Johannes Czernin \\ Ahmanson Translational Imaging Division, Department of Molecular and Medical Pharmacology, David Geffen School of Medicine, \\ UCLA, Los Angeles, California
}

\begin{abstract}
Health care costs in the United States are increasing faster than the gross domestic product (GDP), and the growth rate of costs related to diagnostic imaging exceeds those of overall health care expenditures. Here we show that the contribution of imaging to cancer care costs pales in comparison to those of other key cost components, such as cancer drugs. Specifically, we estimate that ${ }^{18} \mathrm{~F}$-FDG PET or PET/CT accounted for approximately $1.5 \%$ of overall Medicare cancer care costs in 2009. Moreover, we propose that the appropriate use of ${ }^{18} \mathrm{~F}-\mathrm{FDG}$ PET or PET/CT could reduce the costs of cancer care. Because the U.S. health care system is complex and because it is difficult to find accurate data elsewhere, most cost and use assessments are based on published data from the U.S. Centers for Medicare \& Medicaid Services.
\end{abstract}

Key Words: ${ }^{18}$ F-FDG; PET/CT cost; cost-effectiveness; Medicare; CMS

J Nucl Med 2011; 52:86S-92S

DOI: 10.2967/jnumed.110.085621

C

ancer imaging costs have increased faster than overall health care costs in the United States. The rapidly increasing use of PET is a reason for the increased scrutiny of this imaging modality worldwide $(1,2)$. Meanwhile, the National Oncologic PET Registry has provided evidence for the substantial impact of PET on the initial and subsequent management of cancer (3-5).

Recent publications documented significant increases in the use of PET in oncology (6). However, because Medicare reimbursement for PET only started in 1996 and because PET/CT was introduced clinically after the year 2000, high growth rates are not surprising. Because of cost concerns raised by health technology assessment organizations, the use of PET has been limited in many countries. Issues related to such evaluations were recently discussed (2).

Because ${ }^{18} \mathrm{~F}-\mathrm{FDG}$ PET/CT has the reputation of being expensive, it is important to inform patients and health care

\footnotetext{
Received Mar. 3, 2011; revision accepted Jul. 29, 2011.

For correspondence or reprints contact: Johannes Czernin, Ahmanson Translational Imaging Division, Department of Molecular and Medical Pharmacology, David Geffen School of Medicine, UCLA, 10833 Le Conte Ave., CHS-AR-243, Los Angeles, CA 90095.

E-mail: jczernin@mednet.ucla.edu

Guest Editor: Barry Siegel, Mallinckrodt Institute of Radiology

COPYRIGHT @ 2011 by the Society of Nuclear Medicine, Inc.
}

professionals about its actual contribution to overall public (i.e., not privately insured) cancer care expenditures. It is insufficient to simply consider the costs of a single therapeutic or diagnostic approach without considering its overall impact on the downstream costs of health care services. Therefore, we first discuss briefly health care economics terms, such as the cost-effectiveness, cost-utility, or costbenefit of therapeutic or diagnostic interventions. Next, we describe the overall costs of cancer care and analyze the key drivers of these costs. After an analysis of cancer imaging costs in general, we analyze the contribution of PET/CT to these expenditures. Finally, we address the need for large, well-designed clinical trials to determine the value of PET for therapeutic response assessments.

\section{DEFINITIONS OF TERMS}

The impact of various diagnostic modalities has been analyzed in terms of cost-effectiveness, cost-utility, or costbenefit metrics (7), which consider both medical impact (outcome) and costs. In any economic evaluation, it is important to identify costs and, through comparative analyses, to minimize costs. Cost minimization can be achieved through a comparative effectiveness analysis that considers alternative approaches that could result in similar outcomes. Thus, the costs and impact of PET have often been compared with those of existing modalities, such as CT, or with those of "conventional," non-PET approaches.

In cost-effectiveness studies, the impact is usually measured in "natural units," such as life years gained or disability days saved. In cost-utility assessments, the original measures are adjusted to account for patient preference (one additional healthy day would be worth more to someone than one additional bedridden day); the applied metric is commonly referred to as quality-adjusted life years (QALYs). Finally, in costbenefit analyses, the consequence of an intervention, whether diagnostic or therapeutic, is translated into monetary units.

Because assigning a dollar amount to each day of life is open to ethical and political controversy, most medical economic analyses apply cost-effectiveness or cost-utility assessments. For example, the National Institute for Health and Clinical Excellence (NICE) in the United Kingdom uses a threshold of $£ 20,000-£ 30,000$ (in U.S. dollars, $\$ 32,000-\$ 48,000)$ per QALY gained when considering the costs of new treatments for which approval is being sought (8). 


\section{COSTS OF CANCER CARE}

Overall health care costs in the United States amount to more than \$2 trillion/y (9). Health care-related expenditures are predicted to account for $20 \%$ of the U.S. gross domestic product in 2015. This prediction exceeds the overall and per capita health care-related expenditures of any other developed country. In fact, per capita costs in the United States are more than 3-fold higher than those in Spain and more than double those in the United Kingdom (9). Interestingly, these high expenditures are not reflected in a higher life expectancy in the United States than in other developed countries (9).

Cancer care costs are increasing and, including loss of productivity, contribute approximately $10 \%$ to overall health care costs in the United States (9). Direct cancer care costs in the United States totaled $\$ 124.57$ billion in 2010 and are expected to increase to $\$ 173$ billion in 2020 (10). These enormous expenditures are translated into survival benefits in some but not all cancers, and overall improvements in patient outcomes have remained modest (11). Further, the high costs of modest survival benefits frequently do not meet established cost-effectiveness standards (12) because of the coverage of many expensive cancer therapies that often only marginally affect patient outcomes. One example is the inclusion of bevacizumab in second- or third-line regimens for metastatic colorectal cancer. In a randomized study, patients treated with conventional chemotherapy (oxaliplatin, fluorouracil, and leucovorin calcium [FOLFOX]) together with the angiogenesis inhibitor bevacizumab survived for only 2.1 mo longer than those treated with FOLFOX alone (13). If generally applied to this patient population in 2010 , such a regimen would have added $\$ 21,390 /$ patient to Medicare expenditures (14) or a minimum of $\$ 120,000 / \mathrm{QALY}$ gained (assuming that the treatment resulted in 2 mo of good health).

\section{DISTRIBUTION OF CANCER CARE COSTS}

Total Medicare expenditures amounted to approximately $\$ 327$ billion in 2006, and Medicare fee-for-service payments for cancer care accounted for approximately $\$ 32.1$ billion (10\%) of these expenditures (15). In 2006, $47 \%$ of cancer care dollars were spent for inpatient and outpatient care, and physician services accounted for $42 \%$. Hospice care $(8 \%)$, skilled nursing facilities $(<2 \%)$, home health care $(<1 \%)$, and durable medical equipment $(1 \%)$ accounted for the rest (15).

Because particular diagnostic and therapeutic approaches are required for each type of cancer, payments for initial cancer treatments are highly variable. For instance, surgery accounts for more than $50 \%$ of initial colorectal cancer care costs but contributes less than $15 \%$ to initial prostate cancer care expenditures (16). Across all cancers, costs are highest during the initial therapy phase and during the last 12 mo of life. Also noteworthy is that $5 \%-10 \%$ of cancer patients receive chemotherapy during the last month of life (17).
This fact raises ethical issues and economic concerns that are being addressed by professional organizations such as the American Society of Clinical Oncology (18).

In 2004, Medicare paid $\$ 5.3$ billion for cancer drugs, and annual drug expenditures continue to grow at double-digit rates $(19,20)$. The reasons for the high costs of cancer drugs in the United States were recently discussed (21). For instance, patent protection for most drugs lasts for $20 \mathrm{y}$ (from the start of patent approval), creating temporary monopolies. Research and development costs are estimated to be more than $\$ 1$ billion/drug that reaches the market (22), providing pharmaceutical companies with a justification for the high prices of new drugs. However, these data were recently disputed (23).

Third-party payers, such as the Centers for Medicare \& Medicaid Services (CMS), are limited in their ability to negotiate drug prices. For instance, Medicare Part B is obliged by law to cover "any drugs or biologicals used in an anticancer chemotherapeutic regimen for a medically accepted indication," whereas Part D plans are required to include all drugs for "major" or "life-threatening" conditions, with "drugs used in the treatment of cancer" as the model (24). Because of these legal mandates, CMS is in a poor bargaining position in drug price negotiations.

In summary, cancer care costs are increasing rapidly, and drugs are a major contributor to public cancer care expenditures. Given the current legal framework, these facts seem unlikely to change in the near future. Recently, the Cost of Care Task Force of the American Society of Clinical Oncology evaluated the impact of the costs of cancer care on patients, physicians, payers, and industry and recommended several steps to address these issues (18): "These efforts will include an attempt to clarify the drivers of cost in cancer care and suggest ways these drivers can be addressed; define the value of new innovations, with subsequent integration of value into treatment recommendations and guidelines; and develop strategies to mitigate the impact of cost on disparities in access to cancer care."

\section{USE AND COSTS OF IMAGING}

Enormous investments have been made to reduce cancer mortality through better screening; more accurate staging, which can lead to more appropriate therapeutic interventions; and monitoring of tumor responses to treatment, which can affect patient care, outcomes, and costs. The fact that imaging is among the most frequently used tools for accomplishing these tasks has led to the increased use of many imaging modalities in cancer, but annual growth rates have been highest for PET (6).

Using a representative sample from the Medicare fee-forservice database, Dinan et al. (6) evaluated the use and costs of various imaging modalities for patients who were newly diagnosed with leukemia, lymphoma, and lung, prostate, breast, and colorectal cancer ( 6 of the 10 most common types of cancer in patients $65 \mathrm{y}$ old or older) (25). Patients were stratified into 3 groups for which Medicare claims data 
were monitored for 2 y after diagnosis. Group 1 was diagnosed in 1999, group 2 was diagnosed in 2003, and group 3 was diagnosed in 2006. The number of imaging studies for which claims were submitted and the total imaging costs as a fraction of the overall cancer care costs were determined for these 6 types of cancer during the initial $2 \mathrm{y}$ after diagnosis. This analysis revealed that imaging expenditures grew at annual rates of $5.1 \%-10.3 \%$, whereas annual growth rates for overall cancer care costs ranged from $1.8 \%$ to $4.6 \%$. The annual use of PET and PET/CT increased by 35.9\%-53.6\%, depending on the cancer type (6).

Reimbursements for PET have dropped precipitously since its introduction, from $\$ 1,980$ (excluding professional fees and costs of radioisotopes) in 1998 to $\$ 1,151$ (including costs of radioisotopes) in $2010(26,27)$; the largest reduction in reimbursements occurred after the expiration of the "new technology" status of PET. CMS also used facility costs divided by number of scans performed to set a new reimbursement at $\$ 1,375$ in 2002 (28). Using the cost data of Dinan et al. (6) for patients with 6 newly diagnosed major types of cancer, we calculated that imaging expenditures accounted for approximately $4.6 \%$ of overall Medicare cancer care costs. Using their reported numbers of imaging procedures (6) and applying 2006 mean reimbursements $(29,30)$, we estimated that PET contributed $21 \%$ to overall Medicare imaging costs and accounted for approximately $1 \%$ of total Medicare cancer care expenditures. To put this information in perspective, the cost of antianemia drugs not used in end-stage renal disease - most commonly prescribed to treat chemotherapy side effects-accounted for $6.9 \%$ of Medicare cancer care costs in 2006 (15). Figure 1 shows the estimated contribution of imaging to total Medicare cancer care costs (15).

An analysis of actual procedure counts derived from the Medicare Hospital Outpatient Prospective Payment System (HOPPS) yielded similar estimates. A total of 189,662 PET scans were reimbursed under the program in 2006 (29). However, these data do not account for scans performed at independent imaging facilities, which operate $38.6 \%$ of all PET scanners in the United States (1). If we assume the same use rates for independent facilities and hospitals, then the overall number of PET studies reimbursed by Medicare would increase by about $63 \%$ to a total of 308,896 PET scans in 2006. Given an average professional fee of $\$ 131.50$ and an average technical fee reimbursement of $\$ 1,153.72$, the Medicare costs of PET scans would have amounted to $\$ 397$ million in $2006(29,30)$. Using the estimated total Medicare cancer care expenditures of $\$ 32.1$ billion in 2006 (15), we calculated that PET accounted for $1.23 \%$ of Medicare cancer care costs.

Using more recent HOPPS data, we also estimated the increase in Medicare PET expenditures from 2006 to 2009. The number of PET/CT studies in the United States grew to a total of approximately 2 million in 2009 (31). HOPPS accounted for 260,459 of these studies. If we again assume similar PET use by non-hospital-based imaging centers, then we would estimate the total number of Medicare-reimbursed

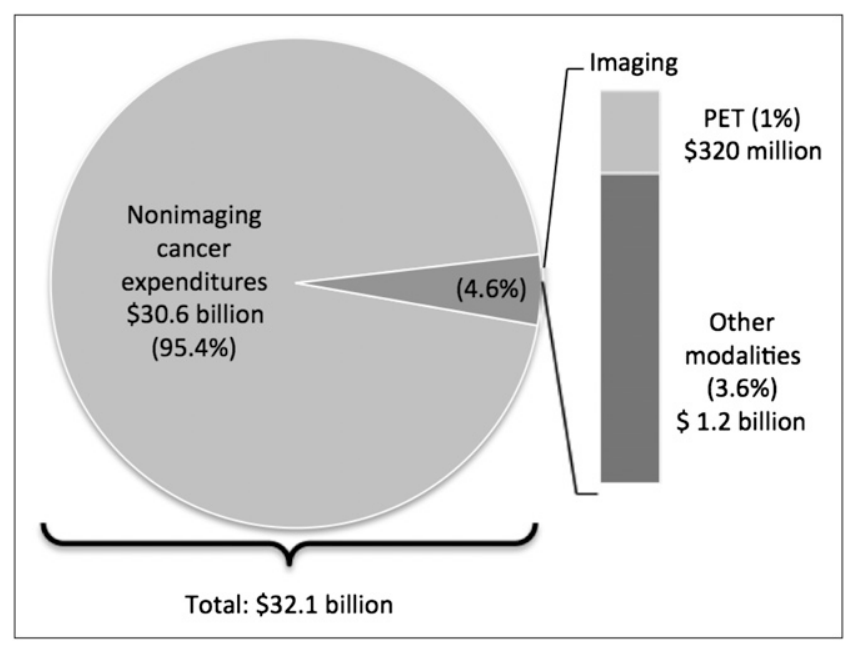

FIGURE 1. Estimated contribution of all imaging modalities and PET alone to total Medicare cancer care expenditures in 2006. Estimates are based on data from Dinan et al. (6) and Potetz and DeWilde (15). These data reflect sample from study of Dinan et al. (6) and do not represent HOPPS or non-hospital-based imaging use data.

PET scans to be 424,000 in 2009. Given a growth rate of $3.25 \% / y$ for total cancer care expenditures (the average growth rate reported by Dinan et al. (6)), estimated Medicare cancer care costs would have amounted to $\$ 35.33$ billion in 2009. Using the 2009 median reimbursement for technical fees $(\$ 1,157)(27)$ and the 2009 national average for professional fees (\$104) (30), we estimated that PET accounted for $1.51 \%$ of Medicare cancer care expenditures in 2009, a $7.0 \%$ annual growth rate from our 2006 estimate.

All of the aforementioned estimates of Medicare expenditures are based on fee-for-service claims, which do not include prescription drugs covered by Medicare Part D. If these costs were included, then the contribution of PET to overall cancer care costs would be lower.

Given these data and a lack of willingness to address major cost issues in cancer care (such as the costs of cancer drugs), reducing imaging-related costs will have a small effect on overall cancer care expenditures. Moreover, a calculation that adds the costs of a single test to overall expenditures largely ignores concepts such as cost-effectiveness, cost-utility assessments, and cost-benefit analyses.

\section{COST-EFFECTIVENESS OF PET}

There are several approaches to addressing the costeffectiveness of ${ }^{18}$ F-FDG PET. Model-based decision tree sensitivity analyses can be used to calculate the costeffectiveness of PET in oncology in the context of initial or subsequent management decisions. Pooled diagnostic accuracy data, procedural costs, disease frequency, and downstream effects were used in such analyses to estimate the cost-effectiveness of PET in managing solitary pulmonary nodules and staging non-small cell lung cancer. These studies suggested that the addition of PET could increase life expectancy without increasing, or by only modestly increasing, cancer care costs $(32,33)$. On the basis of 
these analyses and data from small single-center studies, Medicare reimbursed PET for patients with these diseases.

However, such model-based approaches do have limitations. They do not provide actual cost, cost-effectiveness, or cost-utility data. Models cannot take into account unforeseen and unintended effects that may affect costs or outcomes. Moreover, model input is derived from limited datasets that may have inherent biases.

For addressing these limitations, actual cost-effectiveness data were provided for lung cancer patients whose cancer was staged before surgery in the randomized PLUS study (34). The PET-based approach resulted in a nearly $50 \%$ reduction in futile surgeries (35); if adopted, this approach would have saved Medicare \$30-\$50 million in 2002 (16). A recent study in which ${ }^{18} \mathrm{~F}-\mathrm{FDG}$ PET/CT rather than stand-alone PET was used for the same indication arrived at similar results $(36,37)$.

Another cost-effectiveness analysis, based on actual data from patients whose non-small cell lung cancer was staged, revealed that the inclusion of PET resulted in an additional cost of $\$ 69,563 /$ QALY gained. However, this cost was "within the commonly accepted range for diagnostic tests or therapies" (38).

The Institute for Clinical Evaluative Sciences in Toronto, Ontario, Canada, cited a "distressingly small" number of studies in support of PET and requested more evidence to be developed in clinical trials before PET could be approved (39). Rather than relying on model-based approaches and small clinical studies, the Institute for Clinical Evaluative Sciences opted for generating "convincing evidence" from large, multicenter clinical trials.

A total of 5 studies were commissioned in Ontario, Canada, and 2 of them led to the approval of ${ }^{18} \mathrm{~F}-\mathrm{FDG}$ PET for diagnosing and staging lung cancer $(40,41)$. Two other trials determining the effects of PET on managing colorectal and head and neck cancers are still under way. In another trial, ${ }^{18}$ F-FDG PET was found to be not sufficiently accurate for determining lymph node metastases in breast cancer patients (39); thus, approval for this indication was denied. This decision is consistent with a U.S. Medicare "noncoverage" decision that was based on information published in 2004 (42).

Similarly, in 2000, Australia's Medicare Services Advisory Committee (MSAC) also deemed the evidence to support reimbursement for PET insufficient (43). Only after the publication of the randomized PLUS study (34) was the inclusion of PET for staging non-small cell lung cancer supported. On the basis of parameters specific to the United Kingdom, the report concluded that the use of PET for diagnosing and staging non-small cell lung cancer would cost approximately $£ 9,500$ (\$15,200 in U.S. dollars) per QALY gained (8).

Thus far, the results of these trials, conducted for a limited number of cancers, are consistent with Medicare reimbursement decisions, positive or negative, that were based on the results of many smaller, single-center trials or modeled cost- effectiveness analyses. It remains to be seen whether the ongoing trials in Ontario, Canada, will also result in coverage decisions that are consistent with Medicare policies.

The aforementioned studies demonstrated that PET is cost-effective for some indications. However, for other specific indications, the need for such analyses should be questioned. For instance, PET is increasingly being used for monitoring tumor responses to chemotherapy (44), in particular, for early assessments of neoadjuvant approaches (45). The latter scenario is of considerable interest because patients undergo a given therapy for a set time before undergoing surgery. Importantly, failure to respond to treatment would not result in a switch to an alternative chemotherapeutic approach. Rather, nonresponding patients would be treated surgically once treatment failure was confirmed. Thus, early response assessments could shorten the duration of chemotherapy and thereby reduce costs. Equally as important, this approach could limit costs by reducing the number of hospitalizations due to side effects and the use of palliative interventions required to treat these side effects. Examples of monitoring the effects of neoadjuvant therapy with ${ }^{18} \mathrm{~F}-\mathrm{FDG}$ PET or PET/CT were provided by Lordick et al. (46) for esophageal cancer and by Benz et al. (47) for soft-tissue sarcoma. Their single-center studies did not include cost or cost-effectiveness analyses. However, common to both was that ${ }^{18}$ F-FDG PET or PET/ CT successfully identified treatment responders early during the course of therapy. Neither in esophageal cancer nor in soft-tissue sarcoma would second-line neoadjuvant therapy have been considered. Thus, if accurate, PETguided treatment algorithms could serve as a medically justified mechanism to reduce overall spending on ineffective treatments for patients undergoing neoadjuvant therapy without risking additional downstream costs arising from second- or third-line chemotherapy.

It is also important to recognize that PET-based response misclassifications may carry a smaller-than-expected risk, especially in cancers with low rates of responses to neoadjuvant therapy. For instance, in randomized trials, neoadjuvant chemotherapy and immediate surgery resulted in comparable survival rates for patients with esophageal cancer (48) and soft-tissue sarcoma (49). Thus, multicenter PET-guided adaptive treatment trials of cancers for which the benefits of neoadjuvant therapy are controversial should be conducted to determine whether there are any adverse effects of using PET/CT for early response assessments.

However, early response assessments in patients undergoing adjuvant chemotherapy may increase downstream costs by adding second- or even third-line treatments in nonresponding patients. In such situations, PET-based changes in treatment strategies may improve patient outcomes-but may do so at higher costs.

\section{HOW WILL USE OF PET CHANGE?}

Current Medicare-approved indications for PET in oncology are shown in Table 1.

Costs of Cancer Imaging • Yang and Czernin 


\begin{tabular}{|c|c|c|}
\hline Tumor type & $\begin{array}{l}\text { Initial treatment } \\
\text { strategy }\end{array}$ & $\begin{array}{l}\text { Subsequent } \\
\text { treatment strategy }\end{array}$ \\
\hline Colorectal & Covered & Covered \\
\hline Esophagus & Covered & Covered \\
\hline Head and neck (not thyroid or central nervous system) & Covered & Covered \\
\hline Lymphoma & Covered & Covered \\
\hline Non-small cell lung & Covered & Covered \\
\hline Ovary & Covered & Covered \\
\hline Brain & Covered & CED \\
\hline Cervix & Covered with exception* & Covered \\
\hline Small cell lung & Covered & CED \\
\hline Soft-tissue sarcoma & Covered & CED \\
\hline Pancreas & Covered & CED \\
\hline Testis & Covered & CED \\
\hline Breast (female and male) & Covered with exception ${ }^{\dagger}$ & Covered \\
\hline Melanoma & Covered with exception $\neq$ & Covered \\
\hline Prostate & Not covered & CED \\
\hline Thyroid & Covered & $\begin{array}{l}\text { Covered with } \\
\text { exception or CED§ }\end{array}$ \\
\hline All other solid tumors & Covered & CED \\
\hline Myeloma & Covered & Covered \\
\hline All other cancers not listed & CED & CED \\
\hline \multicolumn{3}{|c|}{$\begin{array}{l}\text { *Cervical cancer nationally not covered for initial diagnosis. } \\
{ }^{\dagger} \text { Breast cancer nationally not covered for initial diagnosis or staging of axillary lymph nodes. } \\
{ }^{\ddagger} \text { Melanoma nationally not covered for initial staging of regional lymph nodes. } \\
\text { \$Thyroid cancer nationally covered for subsequent treatment strategy for recurrent or residual thyroid cancer of follicular cell origin, } \\
\text { eviously treated by thyroidectomy and radioiodine ablation, with serum thyroglobulin level of greater than } 10 \mathrm{ng} / \mathrm{mL} \text {, and negative }{ }^{131} \text { I } \\
\text { hole-body scan results. } \\
\text { CED = coverage with evidence development. } \\
\text { (Adapted from (55).) }\end{array}$} \\
\hline
\end{tabular}

Our analysis of the costs and use of PET was based on data derived from Medicare (6) as well as HOPPS (27). We included Medicare-reimbursed PET studies performed on non-hospital-based PET systems in our analysis. Thus, our estimates do not reflect PET expenditures by private insurers.

Recently expanded Medicare-approved indications for PET in oncology are shown in Table 1. Because of recently broadened Medicare reimbursements, the use of PET is likely to increase within the next few years. However, annual changes in use are difficult, if not impossible, to predict. PET is most frequently used in non-Hodgkin lymphoma and lung cancer. Patients diagnosed with these cancers in 2006 had, on average, 1.1 and 1.0 PET scans, respectively, during the first 2 y after diagnosis. During the same period, these patients underwent, on average, 6.3 and 5.8 CT scans, respectively, per year (6). No analyses are available to elucidate the cost or cost-effectiveness of such a management strategy, which favors CT. However, given the recent consensus of the Imaging Subcommittee of the International Harmonization Project in Lymphoma (50), these data suggest that in patients with lymphoma, the use of PET will increase.

On the basis of the findings of van Tinteren et al. (34), Fischer et al. (36), and Schreyögg et al. (38), the use of PET in patients with non-small cell lung cancer is also likely to increase. This notion is supported by the study of Dinan et al., who revealed that even after 2006, CT scans were performed about 6 times more frequently in patients with newly diagnosed lung cancer than PET studies (6).

Finally, the use of PET for assessing treatment responses is also likely to increase. However, the international imaging community will have to address several important issues before treatment monitoring with PET becomes the standard of care. First, standardization and consolidation of image acquisition, interpretation, and quantification criteria that vary substantially nationally and internationally are required $(51,52)$. Such standardization was proposed recently by working groups in Europe (53) and the United States (54). Second, well-defined prospective multicenter studies that assess actual rather than modeled health care costs and outcomes for various cancers and scenarios, such as neoadjuvant and adjuvant cancer treatments, should be initiated.

\section{CONCLUSION}

Overall imaging costs are increasing faster than overall Medicare cancer care costs. However, PET accounts for only approximately $1.5 \%$ of Medicare cancer care expenditures. 


\section{ACKNOWLEDGMENT}

No potential conflict of interest relevant to this article was reported.

\section{REFERENCES}

1. Buck AK, Herrmann K, Stargardt T, Dechow T, Krause BJ, Schreyogg J. Economic evaluation of PET and PET/CT in oncology: evidence and methodologic approaches. J Nucl Med. 2010;51:401-412.

2. Hicks RJ, Borland J. Are health economics making us sick? J Nucl Med. 2010;51:1665-1667.

3. Hillner BE, Siegel BA, Shields AF, et al. Impact of dedicated brain PET on intended patient management in participants of the National Oncologic PET Registry. Mol Imaging Biol. 2011;13:161-165.

4. Hillner BE, Siegel BA, Shields AF, et al. The impact of positron emission tomography (PET) on expected management during cancer treatment: findings of the National Oncologic PET Registry. Cancer. 2009;115:410-418.

5. Hillner BE, Siegel BA, Shields AF, et al. Relationship between cancer type and impact of PET and PET/CT on intended management: findings of the National Oncologic PET Registry. J Nucl Med. 2008;49:1928-1935.

6. Dinan MA, Curtis LH, Hammill BG, et al. Changes in the use and costs of diagnostic imaging among Medicare beneficiaries with cancer, 1999-2006. JAMA. 2010;303:1625-1631.

7. Drummond MF. Methods for the Economic Evaluation of Health Care Programmes. 3rd ed. Oxford, England: Oxford University Press; 2005.

8. National Institute for Health and Clinical Excellence. Lung cancer: diagnosis and treatment. Available at: http://www.nice.org.uk/guidance/CG24. Issued February 2005. Updated July 5, 2011. Accessed August 11, 2011.

9. Meropol NJ, Schulman KA. Cost of cancer care: issues and implications. J Clin Oncol. 2007;25:180-186.

10. Mariotto AB, Yabroff KR, Shao Y, Feuer EJ, Brown ML. Projections of the cost of cancer care in the United States: 2010-2020. J Natl Cancer Inst. 2011;103:117-128.

11. Parkin DM, Bray F, Ferlay J, Pisani P. Global cancer statistics, 2002. CA Cancer J Clin. 2005;55:74-108.

12. Buxton MJ. Economic evaluation and decision making in the UK. Pharmacoeconomics. 2006;24:1133-1142.

13. Giantonio BJ, Catalano PJ, Meropol NJ, et al. Bevacizumab in combination with oxaliplatin, fluorouracil, and leucovorin (FOLFOX4) for previously treated metastatic colorectal cancer: results from the Eastern Cooperative Oncology Group Study E3200. J Clin Oncol. 2007;25:1539-1544.

14. Centers for Medicare \& Medicaid Services. 2010 ASP drug pricing files. Available at: http://www.cms.gov/McrPartBDrugAvgSalesPrice/01a19_2010aspfiles. asp. Updated June 17, 2011. Accessed August 11, 2011.

15. Potetz L, DeWilde LF. Cancer and Medicare: A Chartbook. Washington, DC: American Cancer Society Cancer Action Network; 2009.

16. Warren JL, Yabroff KR, Meekins A, Topor M, Lamont EB, Brown ML. Evaluation of trends in the cost of initial cancer treatment. J Natl Cancer Inst. 2008;100:888-897.

17. Yabroff KR, Lamont EB, Mariotto A, et al. Cost of care for elderly cancer patients in the United States. J Natl Cancer Inst. 2008;100:630-641.

18. Meropol NJ, Schrag D, Smith TJ, et al. American Society of Clinical Oncology guidance statement: the cost of cancer care. J Clin Oncol. 2009;27:3868-3874.

19. Hoffman JM, Shah ND, Vermeulen LC, et al. Projecting future drug expenditures-2008. Am J Health Syst Pharm. 2008;65:234-253.

20. Medicare Payment Advisory Commission. Report to Congress: Variation and Innovation in Medicare, 6/06 Update. Washington, DC: Medicare Payment Advisory Commission; 2006

21. Brock DW. Ethical and value issues in insurance coverage for cancer treatment. Oncologist. 2010;15(suppl 1):36-42.

22. Gagnon MA, Lexchin J. The cost of pushing pills: a new estimate of pharmaceutical promotion expenditures in the United States. PLoS Med. 2008;5:e1.

23. Light DW, Warburton R. Demythologizing the high costs of pharmaceutical research. Biosocieties. 2011;6:34-50.

24. A Bill to Amend Title XVIII of the Social Security Act to Provide for a Voluntary Program for Prescription Drug Coverage Under the Medicare Program, to Modernize the Medicare Program, and for Other Purposes (brief title: Medicare Prescription Drug, Improvement, and Modernization Act of 2003) (PL 108-173; December 18, 2003). United States Statutes at Large 117(2003):2066-2480.

25. National Cancer Institute. SEER cancer statistics review 1975-2008. Available at: http://seer.cancer.gov/csr/1975_2008/browse_csr.php. Accessed August 11, 2011.

26. Health Care Financing Administration. National coverage determination (NCD) for PET (FDG) for lung cancer. Available at: http://www.cmms.hhs.gov/
medicare-coverage-database/details/ncd-details.aspx?NCDId=301\&ncdver=2\&bc= AgAAQAAAAAAA\&. Accessed September 2, 2011.

27. Centers for Medicare \& Medicaid Services. 2011 OPPS final median files. Available at: http://www.cms.gov/apps/ama/license.asp?file=/HospitalOutpatientPPS/ Downloads/CMS_1504_FC_Medians_Files.zip. Accessed May 11, 2011.

28. Madden Yee K. PET advocates urge CMS to rethink proposed reimbursement rates. AuntMinnie.com Web site. Available at: www.auntminnie.com/index.asp? $\sec =$ ser\&sub $=$ def\&pag $=$ dis\&itemID $=56259$. Published September 30, 2002. Accessed August 11, 2011

29. Centers for Medicare \& Medicaid Services. Median costs for hospital outpatient services, by ambulatory payment classification (APC) group CY 2008. Available at: http://www.cms.gov/HospitalOutpatientPPS/Downloads/CMS1392FC_Median_ File_by_APC.zip. Accessed January 11, 2011.

30. Centers for Medicare \& Medicaid Services. Physician fee schedule look-up. Available at: http://www.cms.gov/apps/physician-fee-schedule/overview.aspx. Updated June 7, 2011. Accessed August 11, 2011.

31. Burns M. The Market for PET Radiopharmaceuticals \& PET Imaging. Las Vegas, NV: Bio-Tech Systems; 2010.

32. Gambhir SS, Hoh CK, Phelps ME, Madar I, Maddahi J. Decision tree sensitivity analysis for cost-effectiveness of FDG-PET in the staging and management of non-small-cell lung carcinoma. J Nucl Med. 1996;37:1428-1436.

33. Gambhir SS, Shepherd JE, Shah BD, et al. Analytical decision model for the cost-effective management of solitary pulmonary nodules. J Clin Oncol. 1998; $16: 2113-2125$.

34. van Tinteren H, Hoekstra OS, Smit EF, et al. Effectiveness of positron emission tomography in the preoperative assessment of patients with suspected non-smallcell lung cancer: the PLUS multicentre randomised trial. Lancet. 2002;359: 1388-1393.

35. Verboom P, van Tinteren H, Hoekstra OS, et al. Cost-effectiveness of FDG-PET in staging non-small cell lung cancer: the PLUS study. Eur J Nucl Med Mol Imaging. 2003;30:1444-1449.

36. Fischer B, Lassen U, Mortensen J, et al. Preoperative staging of lung cancer with combined PET-CT. N Engl J Med. 2009;361:32-39.

37. Søgaard R, Fischer BM, Mortensen J, Højgaard L, Lassen U. Preoperative staging of lung cancer with PET/CT: cost-effectiveness evaluation alongside a randomized controlled trial. Eur J Nucl Med Mol Imaging. 2011;38: 802-809.

38. Schreyögg J, Weller J, Stargardt T, et al. Cost-effectiveness of hybrid PET/CT for staging of non-small cell lung cancer. J Nucl Med. 2010;51: 1668-1675.

39. Evans WK, Laupacis A, Gulenchyn KY, Levin L, Levine M. Evidence-based approach to the introduction of positron emission tomography in Ontario, Canada. J Clin Oncol. 2009;27:5607-5613.

40. Maziak DE, Darling GE, Inculet RI, et al. Positron emission tomography in staging early lung cancer: a randomized trial. Ann Intern Med. 2009;151:221228, W-48.

41. Ung YC, Sun A, MacRae R, et al. Impact of positron emission tomography (PET) in stage III non-small cell lung cancer (NSCLC): a prospective randomized trial (PET START). J Clin Oncol. 2009;27(suppl):abstract 7548.

42. Wahl RL, Siegel BA, Coleman RE, Gatsonis CG. Prospective multicenter study of axillary nodal staging by positron emission tomography in breast cancer: a report of the Staging Breast Cancer with PET Study Group. J Clin Oncol. 2004;22:277-285.

43. Medicare Services Advisory Committee. Positron Emission Tomography: Technology Assessment Report. Canberra, New South Wales, Australia: Commonwealth of Australia; 2000.

44. Weber WA, Grosu AL, Czernin J. Technology insight: advances in molecular imaging and an appraisal of PET/CT scanning. Nat Clin Pract Oncol. 2008; 5:160-170.

45. Quarles van Ufford HM, van Tinteren H, Stroobants SG, Riphagen II, Hoekstra OS. Added value of baseline ${ }^{18} \mathrm{~F}$-FDG uptake in serial ${ }^{18} \mathrm{~F}$-FDG PET for evaluation of response of solid extracerebral tumors to systemic cytotoxic neoadjuvant treatment: a meta-analysis. J Nucl Med. 2010;51:1507-1516.

46. Lordick F, Ott K, Krause BJ, et al. PET to assess early metabolic response and to guide treatment of adenocarcinoma of the oesophagogastric junction: the MUNICON phase II trial. Lancet Oncol. 2007;8:797-805.

47. Benz MR, Czernin J, Allen-Auerbach MS, et al. FDG-PET/CT imaging predicts histopathologic treatment responses after the initial cycle of neoadjuvant chemotherapy in high-grade soft-tissue sarcomas. Clin Cancer Res. 2009;15: 2856-2863.

48. Kelsen DP, Winter KA, Gunderson LL, et al. Long-term results of RTOG trial 8911 (USA intergroup 113): a random assignment trial comparison of chemotherapy followed by surgery compared with surgery alone for esophageal cancer. J Clin Oncol. 2007;25:3719-3725. 
49. Gortzak E, Azzarelli A, Buesa J, et al. A randomised phase II study on neoadjuvant chemotherapy for 'high-risk' adult soft-tissue sarcoma. Eur J Cancer. 2001;37:1096-1103.

50. Juweid ME, Stroobants S, Hoekstra OS, et al. Use of positron emission tomography for response assessment of lymphoma: consensus of the Imaging Subcommittee of International Harmonization Project in Lymphoma. J Clin Oncol. 2007;25:571-578.

51. Graham MM, Badawi RD, Wahl RL. Variations in PET/CT methodology for oncologic imaging at U.S. academic medical centers: an imaging response assessment team survey. J Nucl Med. 2011;52:311-317.

52. Beyer T, Czernin J, Freudenberg LS. Variations in clinical PET/CT operations: results of an international survey of active PET/CT users. J Nucl Med. 2011;52:303-310.
53. Boellaard R, O'Doherty MJ, Weber WA, et al. FDG PET and PET/CT: EANM procedure guidelines for tumour PET imaging-version 1.0. Eur J Nucl Med Mol Imaging. 2010;37:181-200.

54. Wahl RL, Jacene H, Kasamon Y, Lodge MA. From RECIST to PERCIST: evolving considerations for PET response criteria in solid tumors. J Nucl Med. 2009;50(suppl 1):122S-150S

55. Centers for Medicare \& Medicaid Services. National coverage determination (NCD) for positron emission tomography (FDG) for oncologic conditions (220.6.17). Available at: https//www.cms.gov/medicare-coverage-database/detailsncd-details.asp ?NCDId $=331 \&$ ncdver $=3 \&$ NCAId $=85 \&$ NcaName $=$ Positron +Emission + Tomography $+\% 28$ FDG $\% 29 \&$ IsPopup $=y \& b c=$ AAAAAAAAIAAA\&. Accessed August 11, 2011 